\title{
Non-invasive quantification of exercise-induced changes in regional left ventricular function in normals and patients with one vessel coronary artery disease using radionuclide ventriculography
}

\author{
M. Pfisterer and H. Emmenegger \\ Division of Cardiology, Department of Internal Medicine and Division of Nuclear Medicine, \\ Institute of Radiology, University Hospital, Basel, Switzerland
}

KEY WORDS: Regional ejection fraction, radionuclide ventriculography, exercise testing, one vessel coronary artery disease, ischemia, scar, reproducibility.

To quantitate changes in regional left ventricular function induced by ischemia or scar, rest and exercise equilibrium radionuclide studies of 26 patients with one vessel coronary artery disease and 12 normal individuals were analysed with a new method for regional ejection fraction determination. A computer algorithm provided observer-independent segmental analysis from a centre of gravity of the left ventricular activity at end-diastole (left anterior oblique projection). Special segments were assigned for anteroseptal, inferoapical and posterolateral areas corresponding to the three main coronary arteries. Reproducibility using an unchanged camera positioning was excellent even for 2 min acquisition studies ( $r=0.93)$ and still good after repositioning $(r=0.80$ to 0.87$)$. In normal areas, regional ejection fraction increased or showed no change during exercise. In contrast, it decreased significantly in regions supplied by stenosed coronary arteries (ischemia) and remained depressed in scar zones. The method proved to be valid for regional changes induced by left anterior descending and left circumflex coronary obstructions, but less for right coronary artery lesions. Global ejection fraction reflected a sum of all regional changes implying that regional analysis should be more sensitive in detecting coronary artery disease.

Assessment of regional left ventricular performance and wall motion is of particular interest in patients with coronary artery disease (CAD), in whom areas with normal contraction can be found next to hypoor akinetic segments. In some of these patients, regional abnormalities may be detected only during exercise. With the introduction of radionuclide angiography, assessment of global left ventricular ejection fraction at rest and during exercise has become a widely accepted method in the evaluation of patients with $\mathrm{CAD}^{[1-4]}$.

Attempts have been made to describe regional changes of left ventricular function in radionuclide studies. They range from qualitative visual inspection of end-systolic and end-diastolic images or an equilibrium study in movie format ${ }^{[1.5-8]}$ to

Received for publication 30 June 1981; and in revised form 8 October 1981.

Requests for reprints 10: M. Pfisterer, M.D., Division of Cardiology, University Hospital, $\mathrm{CH}-4031$ Basel, Switzerland. description of functional scintigraphic images ${ }^{[9-11]}$ and to quantitative measurement of regional ejection fraction ${ }^{[12-14]}$. Quantitative analyses have so far been restricted to resting studies of 5-15 min acquisition $[9,11,12]$. The results of these different scintigraphic approaches have traditionally been compared with wall motion abnormalities as found with standard contrast ventriculography despite some major differences between the two methods. With contrast ventriculography tangential changes of a two-dimensional body are observed in each projection and certain geometrical assumptions made to describe wall motion abnormalities ${ }^{[15.16]}$. In contrast, in a count-based analysis of equilibrium radionuclide ventriculography, regional ejection fraction provides a measure of change in regional function of a three-dimensional body or sector. While a comparison of global ejection fraction results by both methods is valid, regional changes described by contrast ventriculography (wall motion) and radionuclide ventriculography (func- 
tion) are different. Since localized CAD is the common denominator of these different regional parameters, normal, ischemic and scar contraction patterns should be studied and validated in patients with well defined localized coronary artery lesions.

The aim of our investigation was therefore:

(1) to describe a count-based observer-independent computer method to measure regional ejection fraction from short acquisition equilibrium radionuclide ventriculography,

(2) to define normal values of regional ejection fraction at rest and during exercise,

(3) to describe changes in regional ejection fraction at rest and during exercise in patients with one vessel CAD with and without previous myocardial infarction, and

(4) to assess the reproducibility of such regional ejection fraction measurements in view of later intervention studies.

\section{Methods}

\section{PATIENT SELECTION}

Twenty-six patients with angiographically documented one vessel $C A D$ and 12 normal subjects were included in this study. There were 24 male and two female patients between the ages of 23 and 64 years. Of 16 patients with left anterior descending (LAD) coronary artery disease, nine had proximal $>75 \%$ stenosis with angina pectoris but without previous myocardial infarction. Seven patients had subtotal or total LAD occlusion with documented previous transmural myocardial infarction but without further angina. In the remaining 10 patients the right coronary artery (RCA) was involved in six and the left circumflex coronary artery (LCX) in four. Five of these 10 patients complained of chest pain during the study and five of them gave a history of previous myocardial infarction. All anti-anginal drugs were stopped four days (nitrates $24 \mathrm{~h}$ ) prior to the study in order to avoid drug-effects on global or regional left ventricular function ${ }^{[17,18]}$.

The 12 normal subjects who were all studied for exclusion of CAD, were men between the ages of 31 and 53 years. They were all free of clinical signs or symptoms of disease and had normal ECGs and myocardial perfusion scintigraphy with thallium201 both at rest and during exercise. In addition, they all had a normal global ejection fraction response to exercise ${ }^{[3]}$ and eight of them had angiographically documented normal coronary arteries.

\section{RADIONUCLIDE VENTRICULOGRAPHY}

Radionuclide data were accumulated at rest and continuously during exercise for left ventricular ejection fraction determination as previously described ${ }^{[19]}$. Multiple gated equilibrium radionuclide angiograms were performed by in vivo labeling of red blood cells with $20 \mathrm{mCi}$ technetium $-99 \mathrm{~m}$ after cold pyrophosphate had been injected $20-30 \mathrm{~min}$ earlier. Imaging was then performed with a single crystal scintillation camera of the Anger-type equipped with a high sensitivity collimator in a $40^{\circ}$ to $50^{\circ}$ left anterior oblique and $5^{\circ}-10^{\circ}$ caudal tilt projection which best allowed separation of the left ventricle from other heart chambers. Data acquisition was accomplished with a commercially available nuclear medicine computer system (Medtronic/MDS-A' ' $^{2}$ system). The cardiac cycles of a $2 \mathrm{~min}$ acquisition period at rest or peak exercise were assembled at corresponding times to generate composite images throughout the heart cycle.

In order to calculate ejection fraction, a rectangular region of interest was arbitrarily placed around the left ventricle at end-diastole. A computer algorithm (MUGE) was used to determine automatically the left ventricle at end-diastole using the second derivative of the count profile. Each subsequent frame was processed at the same threshold level to determine the changing count rate within the left ventricle ('variable' region-ofinterest). A computer-assigned background regionof-interest outside the left lower quadrant of the left ventricle was used to correct for non-cardiac activity. Ejection fraction (EF) was then calculated from the time-activity curve according to the formula: $\mathrm{EF} \quad(\%)=[(\mathrm{CED}-\mathrm{CES}): \mathrm{CED}] \times 100$, where $C E D=$ left ventricular counts at end-diastole and $\mathrm{CES}=$ left ventricular counts at end-systole, each corrected for background.

Ejection fractions calculated by this technique have been shown to correlate well with those determined from biplane cine-angiography ${ }^{[19]}$, the correlation coefficient in our laboratory being $r=0 \cdot 90$. The reproducibility of ejection fraction measurements by this technique has been shown to be excellent $\left.{ }^{20}\right]$.

\section{REGIONAL ANALYSIS}

For regional analysis the computer determined a center of gravity of the left ventricular activity at end-diastole (MDS algorithm). From this center, eight radial sectors of $45^{\circ}$ were defined. Because of overlap with aorta and/or left atrium, three of these eight sectors were excluded from further analysis 


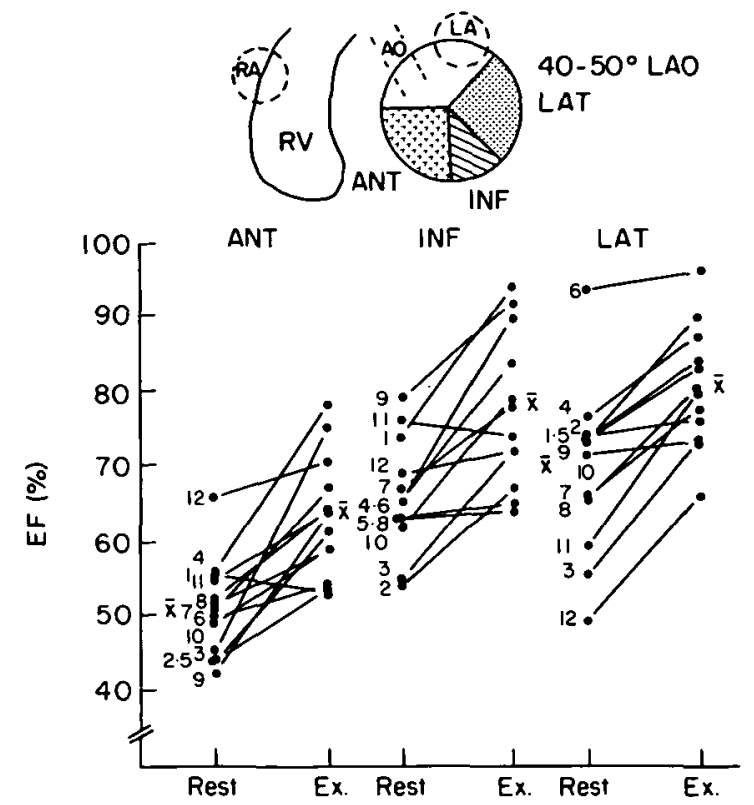

Figure 1 Regional ejection fraction (REF) analysis and normal values at rest and during exercise. Left ventricular activity at end-diastole is divided into eight equal sectors using the center of gravity as starting point. Three sectors are excluded from analysis because of overlap with the aorta (AO) or the left atrium (LA). The remaining five sectors form three regions (ANT =anteroseptal; INF = inferoapical; LAT = posterolateral) reflecting areas normally perfused by the three main coronary arteries. $\mathrm{RA}=$ right atrium; $\mathrm{RV}=$ right ventricle; Ex = exercise; $\mathrm{LAO}=$ left anterior oblique projection; $\overline{\mathrm{x}}=$ mean value; $\mathrm{n}=12$.

(Fig. 1). The remaining five sectors were assigned to the three main coronary arteries: two anteroseptal sectors to the LAD and two posterolateral sectors to the left circumflex (LCX) coronary artery, while there was only one inferoapical sector in the left anterior oblique view which is normally perfused by the right coronary artery (RCA; Fig. 1). The change in counts from end-diastole to end-systole in each sector was used to calculate regional ejection fraction similar to the calculation of global ejection fraction. The same background value determined for global ejection fraction measurement was used for each individual sector.

\section{EXERCISE STUDIES}

All patients and normals underwent supine bicycle exercise on a electronically braked ElemaSchönander ergometer (type EM 350) up to a predetermined exercise level known to produce exercise limiting symptoms. The detector of the scintillation camera was not changed between rest and exercise studies. ECG and blood pressure were monitored during the exercise test. Data of the last $2 \mathrm{~min}$ of exercise were used to calculate global and regional ejection fraction. We have previously shown that this study protocol provided reproducible results for global ejection fraction [20.21].

\section{REPRODUCIBILITY}

To assess reproducibility of two serial measurements of regional ejection fraction at rest, 16 patients selected at random, were studied twice with identical camera positioning. To determine the influence of camera repositioning on regional ejection fraction results, 15 other patients were studied twice with a time interval of 45-90 min between the studies. Both patient and camera were then repositioned according to the same anatomical criteria as used initially. Care was taken that no angles or similar numbers could be noted during the first positioning procedure. In addition, 10 of these 15 patients had submaximal exercise studies twice.

\section{LEFT HEART CATHETERIZATION}

Left heart catheterization was performed in all patients and in eight normal subjects using the transfemoral Judkins technique. Each coronary artery was filmed in at least two, usually three and sometimes four projections. Biplane contrast ventriculography and left ventricular pressure measurements also belonged to the routine left heart catheterization procedure.

\section{STATISTICAL ANALYSIS}

Ejection fraction results are reported as mean \pm 1 standard error of the mean. Regression analysis was performed using the least squares method and Student's t-test for paired and unpaired samples were employed to assess the significance of differences between rest as well as rest and exercise values.

\section{Results}

\section{NORMAL VALUES}

Global ejection fractions of all normal subjects increased during exercise from $56.9 \pm 1.3$ to $66.4 \pm 1 \cdot 1 \%(P<0.001)$. In each individual, exercise ejection fraction was at least $10 \Delta \%$ higher than the resting value ${ }^{3.20]}$.

Normal values of regional ejection fraction at rest and peak exercise are shown in Fig. 1 and summarized in Table 1. At rest, regional ejection fraction 


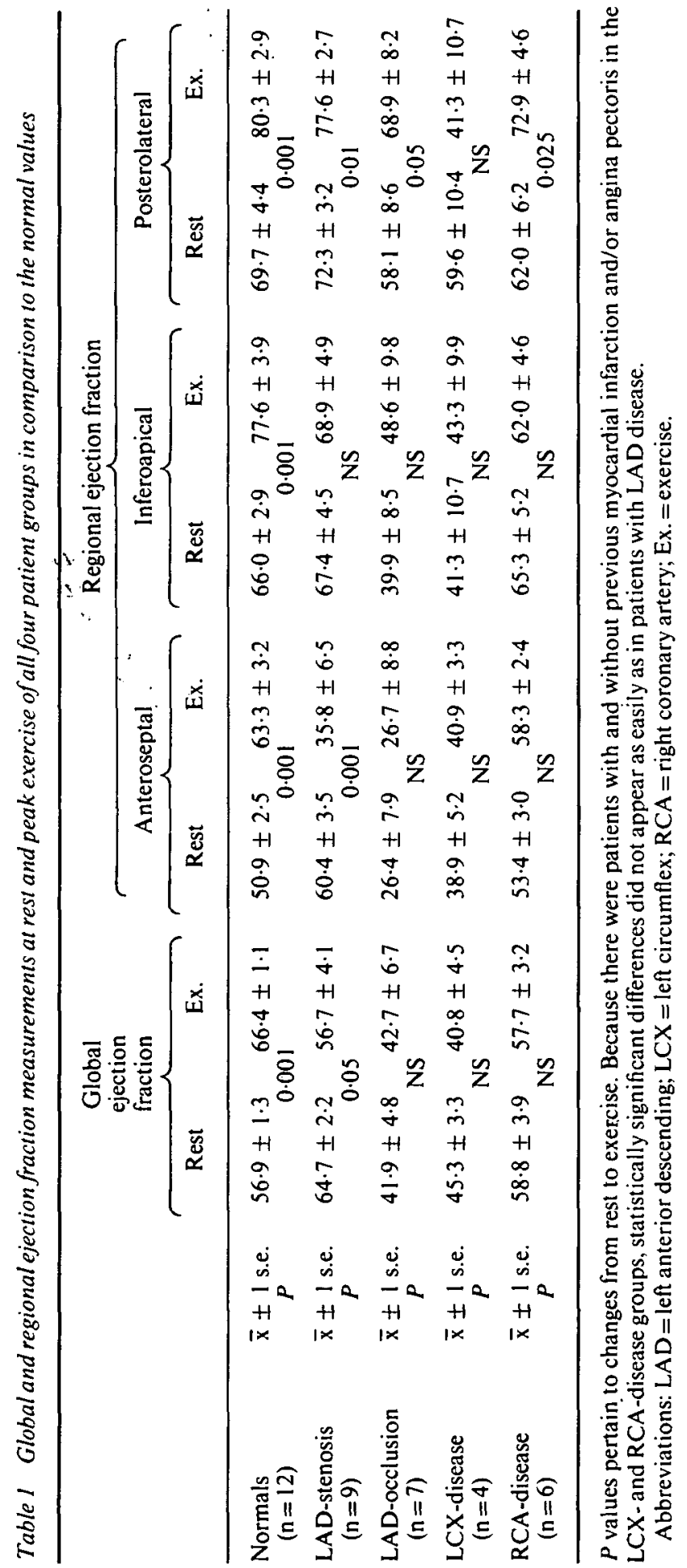



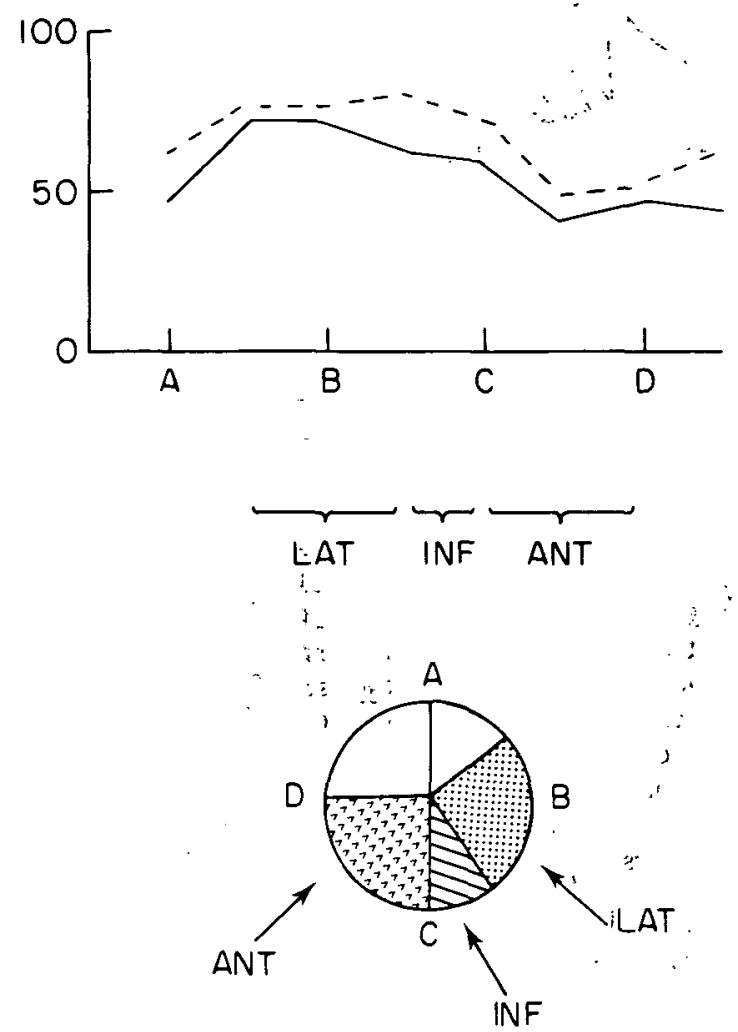

Figure 2 Regional ejection fraction analysis of a normal individual (R.R., male, 37 years). The values of all eight sectors are shown graphically (clockwise) at rest (solid line) and during exercise (dotted line). Regional ejection fraction increases in all sectors. Global EF: rest $=52 \%$; exercise $=66 \%$. Abbreviations as in Fig. 1 .

was significantly lower in the anteroseptal than in the other two areas $(P<0.001)$. During exercise, regional ejection fraction increased significantly in all sectors $(P<0.001)$. Looking at the 36 individual areas of the 12 normal subjects, however, there was a significant improvement of $\geqslant 10 \%$ only in 26 (72\%). On the other hand, regional ejection fraction did not decrease in any normal subject during exercise. Figure 2 shows the computer analysis of all eight segments in a normal subject.

\section{PATIENTS WITH ONE-VESSEL CAD}

In Table 1 and Fig. 3 results of global and regional ejection fraction of 16 patients with single LAD disease are shown in comparison to normal values. In patients with previous myocardial infarction, global ejection fraction was depressed at rest and remained unchanged during exercise. In patients with LAD stenosis and angina, global

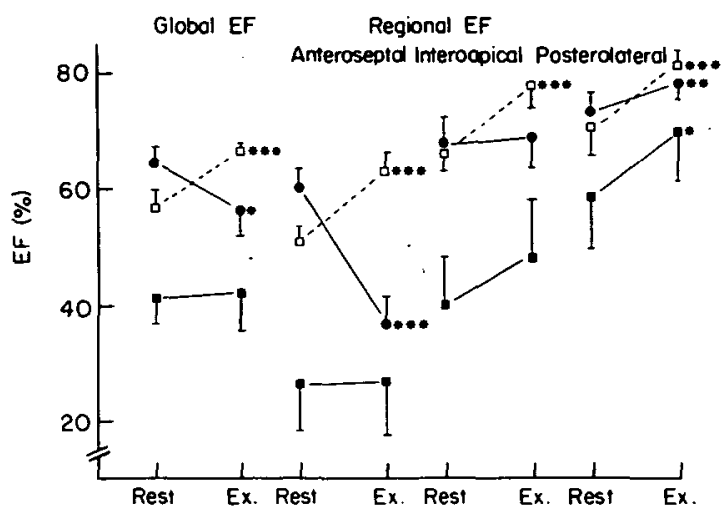

Figure 3 Global and regional ejection fraction in 16 patients with single LAD disease (nine with LAD stenosis and seven with LAD occlusion) in comparison to normal values at rest and during exercise. Note that the main differences between the three groups appear in the involved anteroseptal area whereas all groups showed a normal increase posterolaterally. Abbreviations as in Fig. 1. $\square=$ Normals $(n=12) ; 0=$ LAD stenosis $(n=9)$; Q $=$ LAD occlusion $(\mathrm{n}=7) ; \quad{ }^{*} P<0.05 ; \quad{ }^{* *} P<0.001$; ${ }^{* * *} P<0.005$. Values are $\overline{\mathrm{x}} \pm$ s.e.m.

ejection fraction was normal at rest and decreased significantly $(P<0.05)$ during exercise.

Significant differences in regional ejection fraction became apparent in the involved anteroseptal area, while posterolaterally all patients showed a normal behavior in regional ejection fraction. In the anteroseptal sector, patients with scar due to LAD occlusion showed a depressed regional ejection fraction which did not change significantly during exercise. Patients with LAD stenosis, on the other hand, had a normal regional function at rest but a highly significant decrease of the anteroseptal regional ejection fraction during exercise. In the small inferoapical sector in between there was no significant change in either group.

Figures 4 and 5 show computer analyses of all eight sectors in two patients with LAD stenosis (Fig. 4) and LAD occlusion (Fig. 5), respectively, at rest and during exercise. These individual cases demonstrate how global ejection fractions may remain unchanged despite exercise-induced ischemia and depression of the involved regional ejection fractions due to compensatory increase in regional ejection fraction in non-involved normal areas.

Four patients with single LCX disease followed a very similar pattern of their regional ejection fraction response to exercise in 'opposite' regions compared to those with LAD disease (Table 1): 


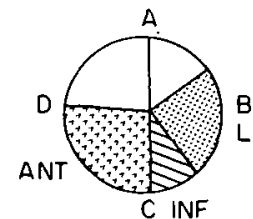

BAT

$100 \Gamma^{(b)}$

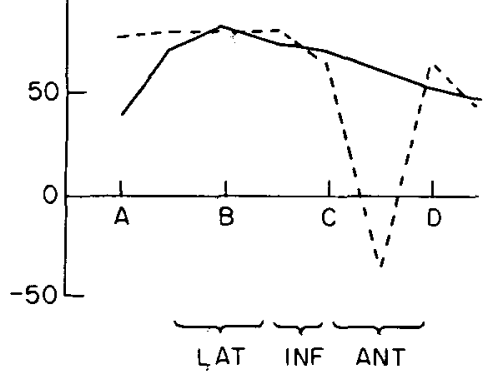

Figure 4 Regional ejection fraction analysis in two patients with single high grade LAD stenosis and exerciseinduced ischemia. Note the marked decrease in regional function in the anteroseptal area. Global ejection fraction did not change significantly due to improvement of regional function in normal regions. Presentation and abbreviations as in Fig. 2. (a) H.M., male, 41 years; global EF: rest $=63 \%$; exercise $=66 \%$. (b) K.B., male, 58 years; global EF: rest $=61 \%$; exercise $=58 \%$.

during exercise, all patients demonstrated a decrease in the posterolateral area and three out of four patients showed some increase anteroseptally. Again in the small inferoapical region in between there was no significant change during exercise.

Six patients with involvement of the right coronary artery showed no significant change in the inferoapical region; regional ejection fraction decreased by more than $10 \%$ in only two of them. A normal increase was found in three patients in the anteroseptal area and in all patients posterolaterally (Table 1).

\section{REPRODUCIBILITY}

Reproducibility of two serial regional ejection fraction analyses covering all three areas are shown in Fig. 6 in comparison to that of global ejection fraction. Reproducibility was excellent in all three regions although it was clearly worse than that of global ejection fraction. The mean difference between two serial measurements of regional ejection fraction was $0 \cdot 16 \pm 5 \cdot 17$ (1 s.d.) implying that a change in regional ejection fraction would

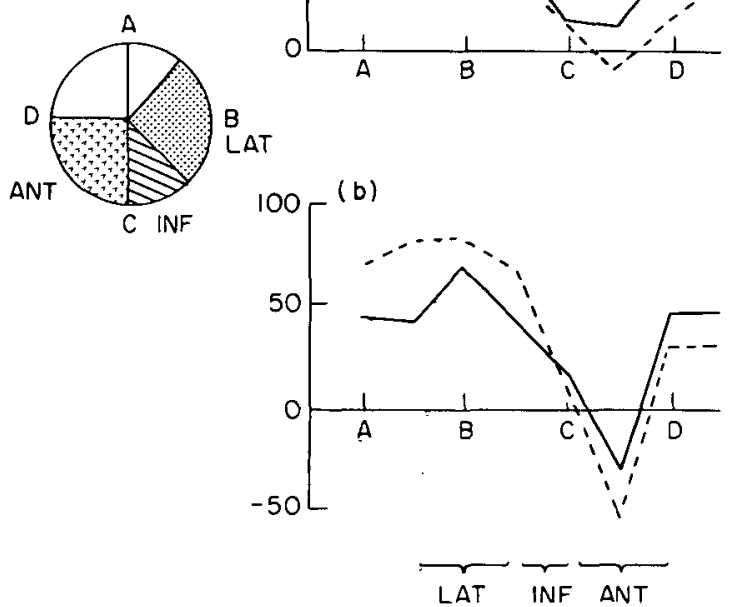

Figure 5 Regional ejection fraction analysis in two patients with single LAD ocelusion due to previous myocardial infarction. Note the depressed regional function in the anteroseptal area at rest which was reduced only a little more during exercise. Presentation and abbreviations as in Fig. 2. (a) D.B., male, 40 years; global EF: rest $=65 \%$; exercise $=34 \%$. (b) R.K., male, 58 years; global EF: rest $=33 \%$; exercise $=34 \%$.
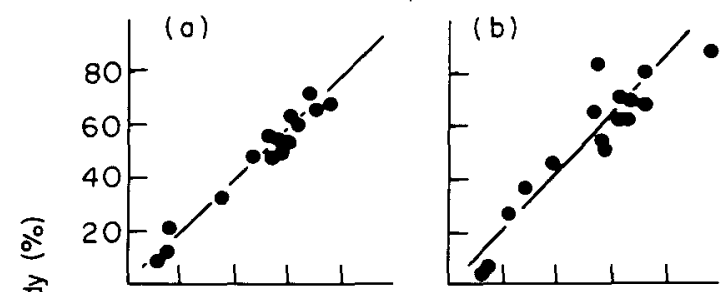

总

$\bar{\omega}$
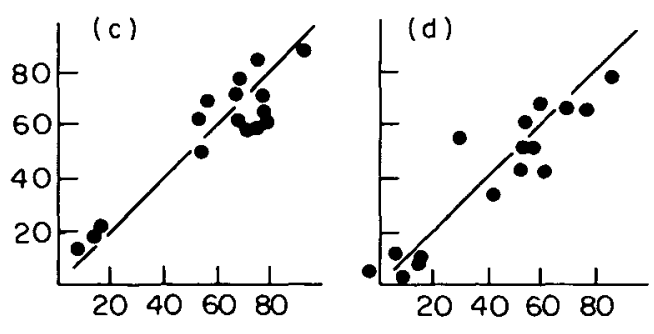

2nd study (\%)

Figure 6 Reproducibility of global and regional ejection fraction measurements of two consecutive studies of 2 min data acquisitions with unchanged camera position. (a) EF global: $r=0.987 ; y=1.05 x-1.5$. (b) REF inferior: $r=0.931 ; y=0.90 x+3.2$. (c) REF lateral: $r=0.925$; $y=0.99 x+1.8$. (d) REF anterior: $r=0.916$; $y=0.96 x+3.9$. 
have to be $\geqslant 10 \%$ ( 2 s.d.) in an individual patient to be 'significant'.

After repositioning, reproducibility was somewhat reduced in all three regions: the corresponding $r$ values ranged between $r=0.80$ and $r=0.87$ while reproducibility of global ejection fraction was still excellent $(r=0.97)$. Variability between two measurements was somewhat larger after repositioning: in anteroseptal and posterolateral areas the mean difference was $0 \cdot 19 \pm 7.19$ and reached $0.71 \pm 9.97$ inferoapically. Under these circumstances a change in regional ejection fraction in a single patient could be considered to be 'significant' only if it were $\geqslant 14 \%$ ( 2 s.d.; anteroseptal and posterolateral regions) and $\geqslant 20 \%$ ( 2 s.d.; inferoapical segment), respectively.

\section{Discussion}

In patients with CAD, quantitative assessment of regional changes in left ventricular contraction has become very important in differentiating between normal, ischemic and scar segments. Area, chord and radial methods have been compared for contrast ventriculography each showing advantages and disadvantages ${ }^{[1,16,22,23]}$. Some of these analyses have been applied to radionuclide ventriculography at rest $[11,12]$. In the present investigation, we have validated a radial method for regional ejection fraction calculation from short acquisition equilibrium radionuclide ventriculography in normal subjects and patients with one-vessel CAD. Comparing rest and exercise measurements, we could separate regions with normal, ischemic and scar myocardium and relate these findings to coronary anatomy. For validation purposes we have studied regional changes in normal subjects and patients with one-vessel CAD thereby avoiding a comparison between regional function (radionuclide ventriculography) and wall motion (contrast ventriculography).

The results of regional ejection fraction at rest showed lower values for anteroseptal as compared to other regions. Others have described a similarly reduced motion of the septal wall in radionuclide studies ${ }^{[5,8,16]}$ or noted a somewhat lower function in that region[12.13], but it remains unclear whether this is a true finding or rather due to the technique applied. In our analysis two possible reasons could be found for a methodological explanation of lower regional function in the anteroseptal area: first, we have used a center of gravity fixed at end-diastole while in reality this center should move during systole towards the septum and aortic valve plane. This movement would reduce regional end-systolic volume and increase regional ejection fraction in the anteroseptal sector and have opposite effects on posterolateral measurements. Due to increased difficulty in accurately defining end-systolic regions we did not attempt to correct for this factor. A second reason may lie in background subtraction: for all regional ejection fractions, we used the same computer-assigned background region-of-interest outside the left lower quadrant of the left ventricle used for global ejection fraction determinations. Actually, background is higher in the septal as compared to the lateral area due to scatter from right ventricular activity[24]. A higher background subtraction in the septal region would result in higher regional ejection fraction values there. Since background is not uniform in this area and since manually assigned regions show larger variability[24], we used only one standard background region-of-interest. This observer-independent method could thus be used both for rest and exercise studies of only short acquisition times.

With the method of regional analysis used, the base of the heart was excluded due to anatomic overlap with the left atrium and due to interference with activity of the aortic root. The remaining five sectors were assigned to three regions corresponding to the myocardium perfused by the three main coronary arteries. While a greater number of segments might have been more sensitive to small areas of abnormality, this advantage would have been lost by the smaller number of counts and the worse statistics in each segment - especially in view of short acquisition times (exercise)[25]. In the present study this problem was exemplified by the increased variability of regional ejection fraction in the small inferoapical segment compared to the larger anteroseptal and posterolateral regions (two segments). Thus, the method used represents a practical compromise between the number of regions analysed and acceptable count statistics despite short acquisition time.

Reproducibility of regional ejection fraction measurements proved to be excellent, but our $r$ values were somewhat lower than those of another report ${ }^{[12]}$, probably due to the short acquisition times used (lower count statistics). One important factor influencing regional analysis of left ventricular function proved to be camera positioning: reproducibility was worse, especially in the inferoapical segment - but still acceptably good-if patient and camera were repositioned for a second 
study. For intervention studies, this implies that small changes can be detected more easily with an unchanged camera position. With proper equipment this can also be achieved during rest-exercise studies.

During exercise, regional ejection fraction increased in normal subjects in all areas, but there were important interindividual variations. Only 26 out of 36 regions in the 12 normal subjects showed a significant increase of $>10 \%$, but there was no decrease. In contrast, in patients with ischemic segments we found a highly significant reduction in regional ejection fraction in the involved area. In normal regions, they showed generally a normal increase in regional function during exercise. This could explain why global ejection fraction did not fall during exercise in some patients despite regional ischemia. Patients with previous transmural myocardial infarction had depressed regional function in the involved area with no? change during exercise. In normal regions, these patients also showed a normal improvement in regional function during exercise.

With regard to coronary anatomy, the study demonstrated that changes in regional function in the anteroseptal and posterolateral sectors were related to obstruction of LAD and LCX coronary arteries, respectively. On the other hand, lesions of the right coronary were detected by significant changes in the inferoapical sector only in a minority of cases. In some of these patients, depressed function in the inferoapical segment was associated with depressed regional ejection fraction in the adjacent segments, mainly the inferoseptal region. Because other investigators have found similar difficulties in detecting inferior wall motion abnormalities, right anterior oblique and $70^{\circ}$ left anterior oblique projections have been proposed for this regional analysis ${ }^{[6.7]}$. The relative insensitivity of the inferoapical sector to lesions of the right coronary artery may explain the false negative global ejection fraction results observed in these patients ${ }^{[2,3,21]}$. In addition, in a grossly enlarged left ventricle and especially in the presence of left ventricular aneurysm the center of gravity of enddiastolic activity is markedly displaced and therefore the methodological approach used is no longer valid. Despite the fact that none of our patients with previous transmural infarction had a left ventricular aneurysm, it is possible that in enlarged hearts such a mechanism might have been responsible for the moderately reduced regional function observed in normal areas of some of these patients. Thus, this methodological limitation in patients with left ventricular aneurysms which is similarly true for other approaches has to be kept in mind in the application of such a regional function analysis.

This study demonstrated that normal, ischemic and scar myocardial regions could be differentiated by non-invasive assessment of left ventricular regional function using equilibrium radionuclide ventriculography. The global ejection fraction response to exercise reflected a sum of all regional changes implying that regional analysis should be more sensitive in detecting CAD. In normal areas, regional ejection fraction increased or showed no change during exercise whereas it decreased in regions supplied by stenosed coronary arteries (ischemia) and remained depressed in scar zones. Thus, in patients with CAD, normal regions could be found next to ischemic or scar areas. The method presented proved to be valid for regional changes induced by LAD and LCX coronary obstructions, but less for right coronary artery lesions. Reproducibility of regional ejection fraction was excellent despite short acquisition times, especially if the camera position was unchanged for baseline and exercise measurements. The implication is that this non-invasive method should be suitable for the quantification of regional changes observed during different drug intervention studies or early after acute myocardial infarction.

We express our thanks to the nuclear medicine technicians of our hospital for their excellent assistance and to H. E. Schmitt, M.D., and his angiographic team for their help in the catheterization procedures.

\section{References}

[1] Borer JS, Bacharach SL, Green MV, et al. Real-time radionuclide cineangiography in the noninvasive evaluation of global and regional left ventricular function at rest and during exercise in patients with coronary artery disease. N Engl J Med 1977; 296: $839-44$.

[2] Bodenheimer MM, Banka VS, Helfant RH. Nuclear cardiology, I. Radionuclide angiographic assessment of left ventricular contraction: uses, limitations and future directions. Am J Cardiol 1980; 45: 661-73.

[3] Pfisterer ME, Slutsky R, Schuler G, et al. Profiles of radionuclide left ventricular ejection fraction changes induced by supine bicycle exercise in normals and patients with coronary heart disease. Cathet Cardiovasc Diagn 1979; 5: 305-17.

[4] Okada RD, Boucher CA, Strauss WH, Pohost GM. Exercise radionuclide imaging approaches to coronary artery disease. Am J Cardiol 1980; 46: 1188-204. 
[5] Okada RD, Pohost GM, Nichols AB, et al. Left ventricular regional wall motion assessment by multigated and end-diastolic, end-systolic gated radionuclide left ventriculography. Am J Cardiol 1980; 45: 1211-8.

[6] Freaman MR, Berman DS, Staniloff HM, et al. Improved assessment of inferior segmental wall motion by the addition of a 70 -degree left anterior oblique view in multiple gated equilibrium scintigraphy. Am Heart J 1981; 101: 169-73.

[7] Brady TJ, Thrall JH, Keyes JW, et al. Segmental wall-motion analysis in the right anterior oblique projection: comparison of exercise equilibrium radionuclide ventriculography and exercise contrast ventriculography. J Nucl Med 1980;21:617-21.

[8] Okada RD, Kirshenbaum HD, Kushner FG, et al. Observer variance in the qualitative evaluation of left ventricular wall motion and the quantitation of left ventricular ejection fraction using rest and exercise multigated blood pool imaging. Circulation 1980; 61:128-36.

[9] Karsch KR, Schicha H, Rentrop P, et al. Qualitative und semiquantitative Analyse der lokalen Wandfunktion mittels der Gated-blood-pool-Methode im Vergleich zur Cineventrikulographie. Z Kardiol 1980; 69: 334-8.

[10] Holman LB, Wynne J, Idoine J, et al. The paradox image: a noninvasive index of regional left ventricular dyskinesis. J Nucl Med 1979; 20: $1237-42$.

[11] Adam WE, Sigel H, Geffers $\mathrm{H}$, et al. Analyse der regionalen Wandbewegung des linken Ventrikels bei koronarer Herzerkrankung durch ein nicht-invasives Verfahren (Radionuklid-Kinematographie). Z Kardiol 1977; 66: 545-55.

[12] Maddox DE, Wynne J, Uren R, et al. Regional ejection fraction: a quantitative radionuclide index of regional left ventricular performance. Circulation 1979; 59: 1001-9.

[13] Papietro SE, Yester MV, Logic JR, et al. Method for quantitative analysis. of regional left ventricular function with first pass and gated blood pool scintigraphy. Am J Cardiol 1981; 47: 618-25.

[14] Pfisterer M. Quantification of exercise-induced wall motion abnormalities assessed by radionuclide angiography in patients with one vessel coronary artery disease. Eur Heart J 1981; 2: (Suppl. A): 114. (Abstract).
[15] Gelberg HJ, Brundage BH, Glanty S, Parmley WW. Quantitative left ventricular wall motion analysis: a comparison of area, chord and radial methods. Circulation 1979; 59:991-1000.

[16] Warren SE, Bhargara V, Vieweg WVR, et al. Semiautomated method for evaluation of left ventricular regional wall motion in coronary artery disease. Am J Cardiol 1980; 46: 832-6.

[17] Battler A, Ross JJ, Slutsky R, Pfisterer M, Ashburn $W$, Froelicher V. Improvement of exercise-induced left ventricular dysfunction with oral propranolol in patients with coronary heart disease. Am J Cardiol $1979 ; 44: 318-24$.

[18] Borer JS, Bacharach SL, Green MV, Kent KM, Johnston GS, Epstein SE. Effect of nitroglycerin on exercise-induced abnormalities of left ventricular regional function and ejection fraction in coronary artery disease. Circulation 1978; 57: 314-20.

[19] Pfisterer ME, Ricci DR, Schuler G, et al. Validity of left-ventricular ejection fractions measured at rest and peak exercise by equilibrium radionuclide angiography using short acquisition times. $J$ Nucl Med 1979; 20: 484-90.

[20] Pfisterer ME, Battler A, Swanson SM, et al. Reproducibility of ejection fraction determinations by equilibrium radionuclide angiography in response to supine bicycle exercise. J Nucl Med 1979; 20:491-5.

[21] Pfisterer ME, Battler A, Slutsky K, et al. Differential diagnosis of atypical chest pain syndromes by equilibrium radionuclide angiography during exercise. Eur J Cardiol 1980; 11:425-34.

[22] Ingels NB, Daughters GT, Stinson EB, Alderman EL. Evaluation of methods for quantitating left ventricular segmental wall motion in man using myocardial markers as a standard. Circulation 1980; 61: 966-72.

[23] Huhmann W, Duangphung K. Left ventricular wall motion. A comparison of six evaluation methods. $Z$ Kardiol 1980; 69: 818-26.

[24] Slutsky R, Pfisterer M, Verba J, et al. Influence of different background and left-ventricular assignments on ejection fraction in equilibrium radionuclide angiography. Radiology 1980; 135: 725-30.

[25] Braun S, Miller H, Schoenberg O, et al. A method for an automated radionuclide assessment of regional ventricular function in the detection of coronary artery disease. First Int Symp Nucl Cardiol, Tel Aviv, 1981: 48. 